\title{
Thoracoscopic sympathectomy; evaluation of technique and advantages
}

\author{
K B Galketiya ${ }^{1}$, V Pinto ${ }^{2}$ \\ Journal of the Ceylon College of Physicians, 2013, 44, 45-46
}

\begin{abstract}
Thoracoscopic sympathectomy is performed for digital ischaemia, hyperhydrosis and chonic pain conditions. When performed by thoracoscopy the morbidity is less than the open procedure. Clear identification of the sympathetic chain prevent the incidence of Horner's syndrome. The procedure could be performed in an acceptable time with insignificant blood loss. Intercostal drainage was not required. The post operative morbidity is minimal with patients being discharged within 48hours.
\end{abstract}

Key words: thoracoscopy, hyperhydrosis, Ischaemic pain, chonic pain.

\section{Introduction}

Thoracic sympathectomy is performed for palmar hyperhydrosis, digital ischaemia and complex regional pain ${ }^{1,2,3}$ which can be performed by an open procedure or thoracoscopy.

The open thoracic sympathectomy is performed by a supraclavicular or transaxillary incision. The incision, division of muscles and retraction causes post operative pain and has a risk of wound infection. The identification of the sympathetic chain may be difficult with risk of damage to the first thoracic ganglion resulting in Horner's syndrome. . $^{1,45}$

In contrast thoracoscopic procedure can reduce the morbidity and provide a clear identification of the sympathetic chain ${ }^{1,4,6}$. The incidence of Horners syndrome by damaging the first thoracic ganglion is low as the highest ganglion accessible by thoracoscopy is the second ganglion. A shorter operating time is possible due to absence of the opening and closing time. The blood loss can be kept to a minimum by using bipolar diathermy and ultrasonic dissector.

This report is an evaluation of the technique, advantages and outcome of thoracoscopic sympathectomy.

\footnotetext{
${ }^{1}$ Consultant Surgeon,

${ }^{2}$ Consultant Anaesthetist, Teaching Hospital, Peradeniya, Sri Lanka.
}

\section{Method}

Thoracic sympathectomy for different indications were performed by thoracoscopy. General anaesthesia with endotracheal intubation was used. Space for dissection was obtained by collapsing the ipsilateral lung with a capnothorax. The collapsed lung was promoted to fall away from the posterior mediastinum by placing the patient to prone position.

Three ports were used. The camera port was placed in the $6^{\text {th }}$ intercostal space just inferior to the angle of the scapula. $\mathrm{CO}_{2}$ insufflation to a pressure of $6-8 \mathrm{mmHg}$ caused the lung collapse partially. Two $5 \mathrm{~mm}$ working ports were placed; $4^{\text {th }}$ intercostal space in the mid axillary line and $8^{\text {th }}$ intercostal space just behind the posterior axillary line. The respiratory and cardiovascular parameters were monitored. The thoracic sympathetic chain was identified. The mediastinal pleura was opened using ultrasonic dissector and the sympathetic chain from the $2^{\text {nd }}$ ganglion to $4^{\text {th }}$ was divided. The blood loss and operative time were noted. At the end of the procedure the lung was expanded while visualized by the camera. Intercostal drainage was not used. Post operatively the patients were managed in the ward.

The analgesic requirement, mobilization, feeding, outcome of surgery and hospital stay were noted.

\section{Results}

Nine patients were operated, 7 males and 2 females. 6 were for digital ischaemia (pain and non healing ulcers of digits), one complex pain syndrome and another with phantom limb. The patient with phantom limb was following an above elbow amputation. One patient had hyperhydrosis and bilateral thoracic sympathectomy was done.

The space provided by lung collapse and prone position was adequate and retractors were not required.

The procedures were completed safely without complications. Respiratory and cardiovascular parameters were stable. There was no measurable blood loss and the average operating time ranged from 20-45 min. There were no conversions to open surgery.

All were managed with oral analgesics, mobilized and fed by same day evening. 
The patient with hyperhydrosis had immediate and complete relief. The patients with digital ischaemia and complex pain syndrome had complete relief of pain. The patient with phantom limb lost the sensation of arm and forearm. He was feeling the hand attached to the amputated stump but no disabling pain.

All were discharged within 48 hours.

\section{Discussion}

Thoracic sympathectomy is an effective treatment for digital ischaemia, hyperhydrosis and complex pain syndromes.

The surgeries of our series were performed under general anaesthesia and both lung ventilation with a capnothorax of $6-8 \mathrm{mmHg}$ to provide partial lung collapse, instead of using one lung ventilation with complete ipsilateral lung collapse. This avoids the potential complications of introducing and managing double lumen tube. ${ }^{7,8}$

Thoracoscopy provided a clear recognition of the sympathetic chain which contributed to the success. The blood loss was insignificant with an acceptable operating time and there were no conversions. Intercostal drainage was not used as the haemostasis was achieved and the lung was inflated under direct vision.

All were mobilized and fed by the same day and had minimal analgesic requirement. They were discharged with in 48 hours. The relief of symptoms was immediate and complete.

\section{Conclusions}

Thoracoscopic sympathectomy is safe and effective. It can be performed with conventional intubation which makes it less complicated and possible in the face of minimal resources. The morbidity is less allowing early discharge from hospital.

\section{References}

1. Kwong KF, Cooper LB, Bennett LA, Burrows W, Gamliel Z, Krasna MJ. Clinical experience in 397 consecutive thoracoscopic sympathectomies. Ann Thorac Surg 2005; 80(3): 1063-6.

2. Han JT, Zhao J, Peng YG. Experience in treatment of Raynaud's syndrome by chemical sympathectomy: 97 cases Department of Vascular Surgery, Peking University Third Hospital, Beijing, China.

3. Ibrahim M, Menna C, Andreetti C, Ciccone AM, D'Andrilli A, Maurizi G, Poggi C, Vanni C, Venuta F, Rendina EA. Twostage unilateral versus one-stage bilateral single-port sympathectomy for palmar and axillary hyperhidrosis Interact. Cardiovasc Thorac Surg 2013; 16(6): 834-8.

4. Singh B, Moodley J, Allopi L, Cassimjee HM. Horner syndrome after sympathectomy in the thoracoscopic era. Surg Laparosc Endosc Percutan Tech 2006; 16(4): 222-5.

5. Allen AY, Meyer DR. Neck procedures resulting in Horner syndrome.Ophthal Plast Reconstr Surg 2009; 25(1): 16-8.

6. Gabrhelik T, Stehlik D, Adamus M, Zalesak B, Michalek P. Radiofrequency upper thoracic sympathectomy in the treatment of critical upper limb ischemia - a case series. Biomed Pap Med Fac Univ Palacky Olomouc Czech Repub 2013; 157(2): 202-8.

7. Jedeikin R, Olsfanger D, Shachor D, Mansoor K. Anaesthesia for transthoracic endoscopic sympathectomy in the treatment of upper limb hyperhidrosis. Br J Anaesth 1992; 69: 349-51.

8. Benumof JL. The position of double-lumen tubes should be routinely determined by fibreoptic bronchoscopy. $\mathrm{J}$ Cardiothorac Vasc Anesth 1993; 7: 513-4.

9. Lee LS, Lin CC, Chung HC, Au CF, Fang HT. A survey on anaesthesia for thoracoscopic sympathetic surgery in treatment of hyperhidrosis in Taiwan. Ann Chir Gynaecol 2001; 90: 209-11.

10. Ojimba TA, Cameron AEP. Drawbacks of endoscopic thoracic sympathectomy. Br J Surg 2004; 91: 264-9.

11. Peden CJ, Prys-Roberts C. Capnothorax: implications for the anaesthetist. Anaesthesia 1993; 48: 664-6. 